a weight of 40 percent to output and 20 percent to each of the other three modules. A limitation of the rankings (but not the scores) is that not all countries are included, which means, particularly for countries with less developed systems, that a country's world ranking may be overstated.

\section{Policy Uses of the Measures}

As is the case with the rankings of universities, most media interest concentrates on the overall national rankings. But it is the scores and rankings for the modules and individual variables, together with the relationships between them, that provide the lessons for higher education policymakers.

Adequate resources combined with a favorable policy environment are necessary for a quality national system of higher education. Lessons can be drawn from looking at the correlations between the scores for the two input modules (resources and the environment) and the end-result modules (connectivity and output). Among the output variables, participation rates and population qualification rates are strongly correlated with expenditure, but it does not matter whether the expenditure is predominantly government financed (as in the Nordic countries) or private (as in Korea). On the other hand, research performance is strongly linked to university expenditure on research and development, which is largely government funded. A measure of the aggregate efficiency of the system is to compare a nation's rank on output measures with that on resources. To illustrate, two countries where the rank on research performance is much higher than the rank for resources are the United Kingdom and China. In both countries, government research funding is targeted to select universities, which suggests this is a quick way to raise research performance. Connectivity is also highly correlated with resources.

\section{Are nations Converging?}

After four annual rankings some trends are noticeable. There has been a continual improvement in most indicators for most countries, so that for a country to keep its ranking it must improve faster than average. There is little evidence of convergence in national systems of higher education over the four years. Using the standard deviation of the scores as a measure of convergence, the overall scores actually show a small increase in divergence and the only module where convergence has occurred is connectivity. But the general finding hides significant movements for individual countries. The greatest improvers are China and South Africa; Chile and Hungary also improved their ranking. Countries that have fallen in rank include Ukraine, Bulgaria, Serbia, Greece, Spain, and Turkey. Within the individual measures some convergence is discernable-for example, in participation rates and expenditure as a share of GDP.

\section{What Systems Perform Best?}

What, then, is the best national system of higher education? No single model dominates. The Nordic countries perform well with a system of relatively close cooperation between universities, government, and business, with high expenditure on research and development; similarly for Switzerland that is particularly strong in domestic and international connectivity. It is a moot point whether this model is possible, or even desirable, in a large economy where lines of communication are more complex. At the other end of the distribution, the more decentralized US system, less reliant on government funding, is ranked first overall. There is, however, one strong conclusion from the rankings: the worst performing national systems are those where there is considerable government control over institutions but low levels of government funding.

In formulating national policies, governments should look at the attributes of countries of similar size and income levels that are performing well. The attributes of a "good" system of higher education depend in part on a country's level of per capita income. At low levels of income there is a need to build up teaching and training; research is best concentrated on importing and spreading new ideas. In an auxiliary U2I ranking, countries are evaluated relative to their levels of GDP per capita. China, India, and South Africa rise up appreciably in the rankings using this measure.

The other side of the coin is to look at how measures such as connectivity, qualification levels, and research expenditure affect economic growth. The lags can be long here and the answers will have to wait for a few more years of data. Ideally, this exercise also requires the inclusion of more low-income countries, but for this better data are needed.

\section{U-Multirank and Latin American Universities}

\section{Ana García De Fanelli}

Ana García de Fanelli is a senior research scholar at the National Council of Research in Science and Technology at the Center for the Study of State and Society in Buenos Aires, Argentina.E-mail: anafan@cedes. org.

$\mathrm{T}$ The first U-Multirank survey was launched in 20I4. It is a multidimensional and user-driven approach to international ranking in higher education, and includes more than 850 higher education institutions worldwide, some 
located in Latin America. This initiative has support and funding from the European Union.

Unlike other international rankings, such as the Academic Ranking of World Universities or the Times Higher Education ranking, that focus is mainly on research activity; U-Multirank addresses also a multiplicity of higher education dimensions such as teaching and learning, knowledge transfer, internationalization, and regional engagement. Additionally, and most importantly, users can select which areas of performance to include when comparing a choice of universities. In addition to data usually employed by other international rankings, such as bibliometric and patent data bases, U-Multirank collects information provided by institutions (via an institutional questionnaire) and students (through a survey of students at participating universities).

Unfortunately, information about nonresearch indicators is available only for a few Latin American (LA) universities. This article discusses whether more LA universities will be able to participate in this interesting and essential initiative in the near future. Similar projects in Latin America are discussed followed by an analysis on whether some of the data requested by U-Multirank in the institutional questionnaires.

\section{U-Multirank addresses also a multi- plicity of higher education dimensions such as teaching and learning, knowl- edge transfer, internationalization, and regional engagement.}

\section{Similar EXPERIENCES IN LATIN AMERICA}

In response to research-oriented international rankings, LA universities have begun to engage in national and international projects, in order to supply data and indicators on the multiple dimensions of their operations and outputs.

The Integrated Information System for Higher Education Institutions in Latin America for the Common Higher Education Area with Europe (INFOACES), funded by the European Commission within the ALFA (Latin American Academic Training) program, has similar goals to UMultirank. The network is comprised of 33 partners from 23 countries (I8 in Latin America and 5 in Europe). The Polytechnic University of Valencia, in Spain, coordinates the project. INFOACES's web site provides users with basic information about universities and their web sites; lists of degrees offered by field of study; the total number of stu- dents at the institution (or the number of students enrolled in each degree program, if the data are available); and the number of faculty at the institution. Universities that are members of the network have access to a restricted database with further information for management decisions. They also have access to the Flexible Professional in the Knowledge Society (PROFLEX). PROFLEX is a platform for the implementation of a monitoring system of graduates through online surveys.

Although limited to Mexican higher education institutions, the Comparative Study of Mexican Universities (EXECUM), a database produced by the Universidad Nacional Autónoma de México, provides insight into additional perspectives. Its web site offers users comparative information with respect to teaching, research, and financing. It even offers specific results related to the Mexican quality-assurance policy, such as accredited programs and the number of researchers from the National System of Researchers (SNI). EXECUM contains areas with somewhat detailed information, such as science and technology; for other areas, such as teaching process and output, there is considerably less information.

\section{Data Requested in Institutional Question naires}

Existing initiatives in Latin America is a good starting point for the progressive inclusion of higher education institutions in U-Multirank. But data requested by the institutional questionnaires on teaching inputs and outputs and on funding issues are quite difficult to obtain from most LA universities.

For example, comprehensive data per institution on international students (especially incoming students and those participating in international exchange programs) are seldom available - the number of students with internships and the number of students who graduated within the standard period of study. With respect to graduates, LA universities, with the exception of some Chilean ones, generally lack a tracking system that makes it possible to identify whether alumni have continued to study or started to work. Some LA universities have a monitoring system for graduates in certain degree programs, but this is not carried out systematically. Some data on funding are also difficult to obtain, in particular the total revenue of institutions per category (core budget, tuition fees, external income from research, and income from licensing agreements). This is particularly challenging in the case of private universities. Finally, it is unclear how the funding of LA universities can actually be apportioned between research, teaching, and knowledge transfer activities.

Of course, we should take into account that the quantity and quality of statistics on LA higher education systems vary per country and even per category of institution. 


\section{CONCLUSION}

The difficulty for LA institutions to collect these data and indicators certainly does not imply that they cannot be part of the U-Multirank or other similar tool, to improve transparency in higher education in the future. To achieve this goal, there should be suitable incentives (increasing potential benefits, lowering transparency costs) for universities to participate. Universities should also provide the right technological, human, and financial resources to produce this information.

Information on the higher education system has the characteristics of a public good: it is nonexclusive and nonrival. If such information is indeed on a public good, then governments have a responsibility to guarantee the provision of this service. It is unlikely that each LA university will on its own initiative produce the necessary quantity and quality of data to satisfy this social demand for higher education statistics. In particular, it is unlikely that they will sustain the effort to regularly collect data on teaching, learning output, and internationalization. To achieve this goal, LA governments must engage in this innovative enterprise and encourage universities, through funding mechanisms and other incentives, to produce information based on performance indicators and to publish them on a regular basis.

\section{The Syrian Refugee Crisis and Higher Education}

\section{Hans de Wit and Philip G. Altbach}

Hans de Wit is professor and director of the Center for International Higher Education at Boston College. E-mail: dewitj@bc.edu. Philip G. Altbach is research professor and founding director of the Center. Email:altbach@bc.edu.

$\mathrm{T}$ The rapidly escalating refugee crisis in Europe has been dominating the international news for several weeks, but surprisingly it is only very recently that the higher education community has become alert to its role and to the considerable dilemmas it will have to face. It is relevant to speculate about the needs and challenges of higher education as a result of this crisis.

The massive exodus of refugees, primarily from Syria, but also from Eritrea, Libya, Afghanistan, the Kurdish territories, and Iraq, numbering in the hundreds of thousands, must be added to already significant numbers trying over the years to move from Africa to Europe. The motivations for this massive migration are both political and economic: the refugees are escaping terrorism, civil war, and poverty in the countries they come from. Over the past several years the attempts of African refugees to cross the Mediterranean have been mainly perceived as a human tragedy resulting from economic hardship, and have received limited support from receiving countries and their communities and governments. The new influx of refugees from the Middle East, in particular Syria, seem to receive a more positive response, at least in Western Europe, although less so in some Central and Eastern European countries such as Hungary.

\section{The motivations for this massive migra- tion are both political and economic: the refugees are escaping terrorism, civil war, and poverty in the countries they come from.}

The Human Capital Potential of Middle East Refugees Why is that the case? In the first place, refugees from Syria escape a country where both the Assad government and Islamic State commit terrible crimes against the local population. They are perceived more as political victims (which fuels sympathy in the receiving countries), than as economic refugees. Refugees from Iraq and the Kurdish territories are seen in similar ways. In addition, and this is where education enters the equation, refugees from Syria, Iraq, and the Kurdish areas are perceived to be better educated and therefore, potentially easier to integrate into society and the labor market in the receiving countries. In the current competition for talent, these refugees are not only seen as victims and a cost factor for the local economy, but in the long run also as welcome new talent for the knowledge economy.

Many media reports feature articulate, English-speaking young professionals from the Middle East expressing their hopes to continue their education or obtain skilled jobs and contribute to European economies.

While struggling with issues of quotas and capacity, Germany is grasping this potential, and other European countries are also beginning to frame their policies in more sophisticated ways. Although the humanitarian factor is understandably dominant in current official statements, the German authorities also make it clear that these refugees can also be an asset for Germany and other European countries in the short and particularly the longer term. German universities are expecting to accept approximately I०,००० of the 800,000 refugees that are now entering the country. 